\title{
Intention to purchase behavior on social e-commerce website across cultures (case study: Iranian online purchaser)
}

\author{
1-Ali Rezaeian \\ Accounting Product Faculty, Shahid Beheshti University, Daneshjoo Blv, Shahid beheshti Sq, Yaman st,Shahid Chamran \\ Highway, Tehran, Iran \\ a-rezaeian@sbu.ac.ir \\ 2-Sajjad Shokouhyar \\ Accounting Product Faculty, Shahid Beheshti University, Daneshjoo Blv, Shahid beheshti Sq, Yaman st,Shahid \\ Chamran Highway, Tehran, Iran \\ s_shokouhyar@sbu.ac.ir \\ 3-Shahabedin Yousefi \\ Unit 4, Number 28, Jahanara 49 alley, Yousefabad, Tehran, Iran \\ Shahabyou@gmail.com
}

\begin{abstract}
With the increasing popularity of social media, millions of users use social media services in the space such as Facebook, Twitter, MySpace, etc. Following that many organizations see this phenomenon as an opportunity to create new business and know this is known as social commerce. This phenomenon is not only due to the growth of social media, but is also because of users' participation in the fate of the marketing and sale of products. So, e-commerce has undergone a revolution, which is affected by the adoption of web 2 functionalities to increase customer participation and achieve greater economic value. Therefore, studying the behavior of buyers in the social commerce platforms can create more value for owners of e-commerce in the context of social commerce. For this reason, attempts were made to obtain more accurate findings regarding the behavior of e-commerce purchasers in social networks by taking into account the moderating influence of culture on it (Iranian online purchasers). This is an applied study. It also considered a descriptive crosssectional study with regards to the way data are collected. The analysis of data collected from 184 active professionals in the IT industry and users of social networks indicates the moderating effect of culture and the mediating role of trust in a social network community in terms of social identity, trust transference (Familiarity), social influence (intimacy and friendship), cognitive style and the intention to purchase in the social business environment. Moreover, these findings also show that trust transference affects intention to purchase in social networks considering the aspects of familiarity, social identity and cognitive style. But the direct effect of social influence (feel close to) on the purchase intention has been rejected.
\end{abstract}

\section{Indexing terms/Keywords}

Social commerce, Cross-cultural study, Social interaction, Trust, Trust transfer, Social network site, Cognitive style, Social identity

\section{Introduction and purpose}

With regards to the fact that social networks, mobiles and e-commerce have become one of the most important concepts of business and has been associated with leading organizations in recent years; and on the other hand, the explosive growth in smart phones, tablets and laptops resulted in quick and easy access to social networks; business owners, in today's complex world, need to specify strategies of advertising, marketing and selling their products and services in the context of social networks in order to achieve the aims and plans of their organizations, as well as to survive and progress in today's rapidly changing environment. This new platform has emerged as "social commerce" and such high number of users has not been seen to date. This important goal is not just attached importance with regards to the above reasons, but also is developed in this context because of the participation and cooperation of users in the fate of the marketing and sales of products. Because instead of considering information provided by manufacturers, buyers check products, read other recommendations on products, study ratings on the products provided by others before buying them online. They also have more bargaining power and choices through internet. Thus, in this environment, customers have achieved the knowledge and social experience that makes them better understand their online shopping purposes and supports and promotes them in making informed and accurate decision in this regard. Meanwhile, the online business will be able to obtain appropriate information from the behavior of their customers and understand their experience and expectation and continue to develop appropriate business strategies accordingly. Therefore, in this study we were trying to build a comprehensive evaluation model for the behavior of e-commerce purchasers in social networks by taking into account the moderating influence of culture on it (Iranian online purchasers). We also proposed fifteen hypotheses and analyzed the accuracy of any of the hypotheses using statistical investigations.

\section{Theoretical Foundations and the research literature}

E-commerce has undergone a revolution, which is affected by the adoption of web 2 functionalities to increase customer's participation and achieve greater economic value. This new phenomenon is proposed as social e-commerce, the dimensions of which are still not fully understood. In addition to the lack of consensus on the definition of social commerce, little research has been done on the social e-commerce (Huang, 2013). In this regard, the social commerce have emerged as quickly as possible as a new field of research for both practitioners and researchers. The subject of this study is 
evaluating the effects social media, technology and social network services on shaping new commercial channels (Zhou, 2013). Researches are carried out in social e-commerce in the following framework:

- Commercial activities such as marketing, sales, comparison, purchase, sharing.

- Social media includes factors connecting markets and communities through online and offline channels

- People who represent community members, vendors, buyers and...

- Information, for example, products and services.

This research framework is called BTIP (business, technology, information and people) (Zhang, 2013).

\section{Social commerce}

Today we are in the midst of other transition, social networks, mobile and local e-commerce are developing and growing in a new and variable environment alongside more traditional e-commerce in retail trade (like what Amazon has implemented). Social network sites such as Facebook, Twitter, YouTube, Pinterest, which enable users to publish their own content (such as movies, music, photos, and personal information, blogs, and applications software) have made outstanding progress. With the explosive growth in smartphones such as iPhones and Android devices, tablets and ultralight laptops, a new e-commerce platform called "e-community" has emerged, which has intertwined with social networks, mobile computing, and social private relations. Such high number of users has not been seen to date. In this regard, various businesses are looking for a proper perspective for advertising, marketing and selling their products and services by considering the social e-commerce (Laudon 2015). More demand for e-commerce business model has imposed major changes on the e-commerce. فيانگZinouri has interpreted social commerce as "society+ e-commerce" . He believes that society plays an indispensable role in the realization of the value of e-commerce (NiknejadKhasmakhi, 2012). Social ecommerce belongs to those e-commerce categories, which benefit from social networks and online social communication as enablers. Social e-commerce is growing by a number of factors, including the increased use of social network logon username in different websites, information and awareness raising (to share acceptance or rejection of a product or service via the Like button in Facebook or Twitter tweet), online collaborative shopping tools, social search (recommended by trusted friends online) (Laudon, 2014). In other words, the social e-commerce is a form of business through social media including the convergence between the online and offline environments (Zhang 2012). In a more comprehensive sense, social e-commerce involves the use of Internet-based media that allow people to actively participate in marketing, sales, comparison, consultation, purchase, and share of products and services in both the market and online and offline communities(Zhou, 2013). In the offline world, a customer' decision to buy a product or service is mainly influenced by friends, family and colleagues. With the advent of internet-based social media, a new kind of communication has come into play between companies and consumers, which competes with traditional marketing ideas as well as new opportunities for organizations to more and more understand customers and communicates with them directly (Zhou, 2014).

Thus, social networks are one of the best places to do business and lead to the emergence of a new concept called social commerce. Social commerce is introduced as using social media in e-commerce, in order to help buy and sell online goods and services. In other words, social commerce will be introduced as interpersonal relationships, such as interests, opinions, recommendations, etc. that affect a business deal.

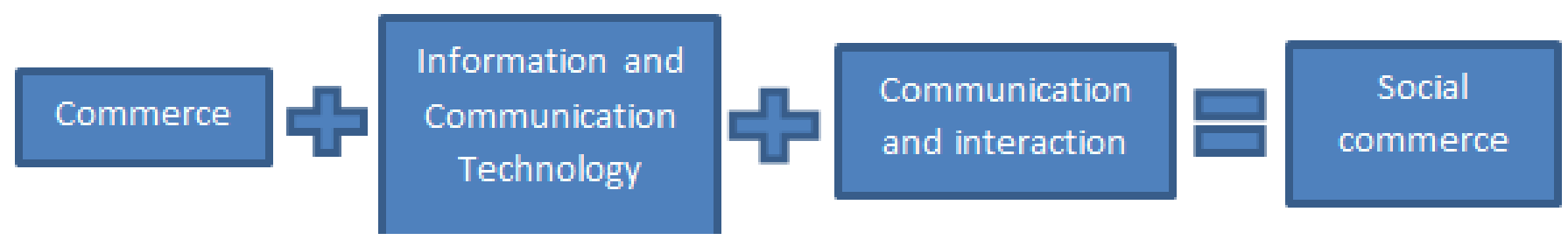

\section{Figure 2-1 Overview of social commerce (NiknejadKhasmakhi, 2012) Effect of social networks on the purchasers' behavior}

Behavior consists of a field of activity or actions and reactions that are formed as a result of internal and external factors. Two factors of availability of goals and expectations significantly affect the shaping the behavior. If a customer experiences a positive relationship with you, $\mathrm{s}(\mathrm{h}) \mathrm{e}$ shows desire for more relationships. This experience is directly or indirectly can be effective. It is important to know that how customers make decisions and behave on what basis. Behaviors are mainly studied with the aim of predicting future behaviors, correcting and controlling behaviors. Accordingly, it is necessary to be able to predict customer's behaviors, and we need to know the why(s) \& wherefore(s) of a behavior, if there was the possibility of correcting and controlling behaviors (Rezaeian, 2015). Motives are the why(s) \& wherefore(s) of behaviors. (Rezaeian, 2015). Previous researches in 2008, 2009 and 2011 showed that social networks (SNs) have created new ways of interactions, new forms of communication between people, decision-making, socialization, learning, cooperation or even purchase. As a result, studies on social media and their effect on the customer's behavior and organizations have been widely considered in academic researches. Moreover, a research problem has been created for marketers and strategy designers (Zhou, 2014). The development of Web 2.0 environment has made preconditions in social commerce sector, in a way that the researches of Chan Hee, an internet technical adviser in China show that Web 
2.0-based social commerce tries to turn the concept into an application.Dong Hee Shinalso believes self-expression, participation, dialogue, creation and maintenance of virtual communities as a basic concept of Web 2.0, help people offer more useful recommendations, more effective search and purchase the goods they are looking for (NiknejadKhasmakhi, 2012). The rapid development of social media in the web 2 context, have great potential for transferring the e-commerce from a product-oriented environment to a social phenomenon and customer-orientated phenomenon (Wigand, 2008). In this environment, customers have achieved the knowledge and social experience, which supports them in better understanding their online shopping goals and making informed and accurate decisions (Dennison, 2009). Meanwhile, the online business will be able to obtain appropriate information from the behavior of their customers and understand their experience and expectation and continue to develop appropriate business strategies accordingly (Constantinides, 2008). Social commerce structure is based the on social networks. This structure is the business center in which each customer is a network node. Structural and relational attributes of the network affect the interactions among consumers and increase the participation level and ultimately strengthen the consumer's interest in the product.

Investigating aspects of the social commerce, structural characteristics of the network and systematic analysis of the impacts of social networks on the customer's behavior and decisions in each stage of the purchase process will help in identifying the effective factors in the purchasing decision. It also enables businesses to understand customers' response on their marketing strategies. Understanding why, where and how customers' purchase improve marketers' competitions will lead to better predict customers' response to their marketing strategies (NiknejadKhasmakhi, 2012). In this regard, the aspects influencing the behavior of e-commerce buyers in social networks are investigated and defined:

\section{Social influence}

The process of influencing thoughts, behavior, and emotions of another person is called influence. And efforts made to optimally influence other individual are called social influence (Rezaeian, 2011). According to Coleman writing, there are three types of social influences including,agreement, identification, and internalization. Among these three, the inner category is more relevant to online social networks and commerce. Inner category is a situation in which a person accepts and agrees with the opinions and behavior of others in both public and private settings (Celeste, 2012).

Consumers talks about their purchase intentions and decisions with family members, relatives, friends and colleagues and may even ask them for their suggestions and recommendations.

As a result, consumers will probably be influenced in their decision making due to their interaction with others. Purchase choices of members will be changed to the extent that members of the virtual community share their attitudes and norms. In addition, the context of readiness to accept the virtual community influence is affected by internalization of norms, which positively affect the purchasing behavior of members (Fathian and Hosseini, 2014).

According to Mead viewpoints on the social identity, any person forms his/her self or identity by organizing his/her social or group attitudes. In other words, the one's image and sense reflects an attitude that people have towards him/her. On the other hand, according to Tajfel, social identity is linked with group membership in a new way. Accordingly, social identity is that part of one's perception from himself/herself that originates from his consciousness of membership in a social group as well as the importance of values and its accompanying feelings. These elements of this approach are:

1) Cognitive element- knowing that the person belongs to a group,

2) Value element - assumptions about the positive and negative value consequences of group membership

3) Emotional element- feelings toward the group and other individuals who have a special connection with them. Therefore, the social identity can be considered a kind of self-knowledge in relation to others (Rezaeian, 2012). Group identity leads to philanthropic and collaborative performance and activities in organizations. Social identity of an association can enhance the influence of virtual community on purchase choices of its members. In online groups and cyberspace, internalization of values and norms is far more powerful due to the impact of non-personalization and anonymity of these groups; because the influence of standards and individual contracts is decreased and the power of external guidance factors is increased in these conditions (Fathian and Hosseini, 2014)

Studies on trust transference show that trust may be transferred from one source to another (Celeste, 2012). For example, trust is transferred among members in an organization. A person's trust i different fields may be transferred into another person.

Organizational trust includes a personality trait called readiness ness to trust others. This readiness can be considered as a general willingness to trust others (Rezaeian, 2012). In the virtual community, members who trust the ability and knowledge of others are more willing to share information and accept the shared information. This is a natural issue for them to interact and exchange information with those who have knowledge and expertise on the topics discussed and services offered in the virtual community (Fathian and Hosseini, 2014). Cognitive style refers to activities by which human solve the discrepancy between the internalized perception of the environment with what has really been understood from the same environment. Although two people have the same choices, they rarely follow a decision-making process. The word "Cognition" refers to the way through which people can interpret the information. Therefore, the cognitive style is the ways through which people organize information during decision-making. Cognitive styles can be classified based on two axes: (Rezaeian, 2012). 

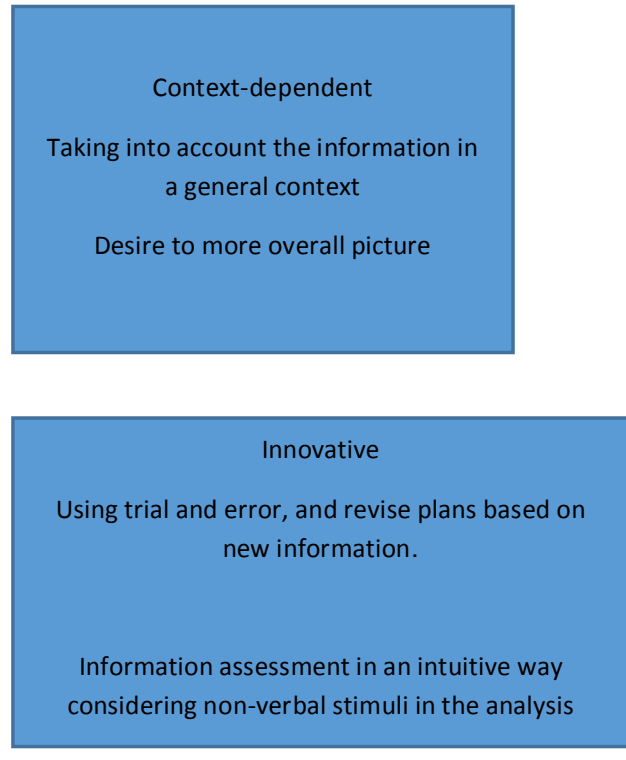
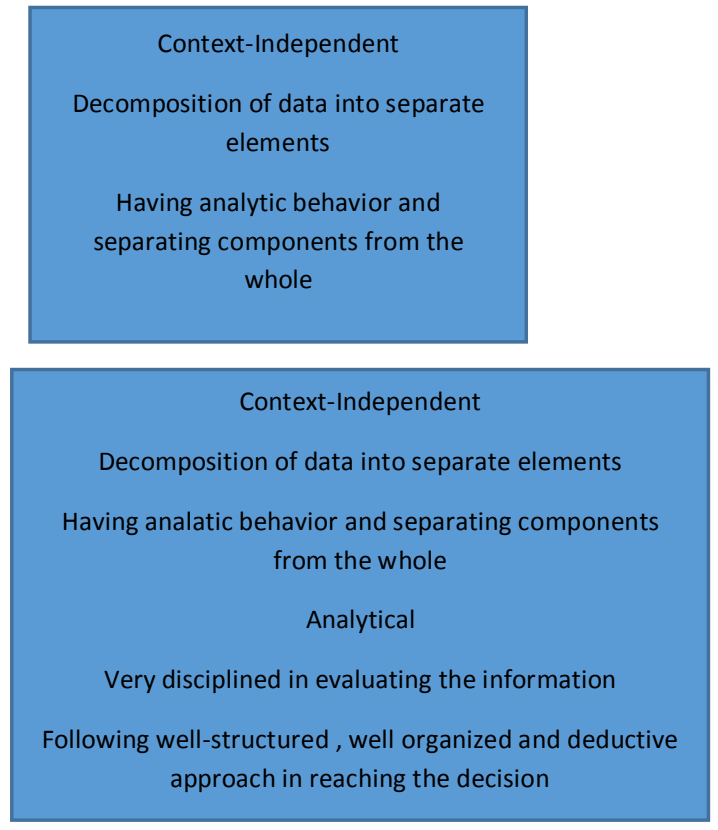

Figure 2.4. Cognitive style (Rezaeian, 2012)

Increased attention from managers in virtual companies to cognitive, experiential, personality antecedents and the emotional state increases the trust and reduces the perceived risk of online customers and ultimately strengthen their purchase intention (Montazeri et al., 2014). Matching the characteristics of the site with the cognitive style increases online sales. This subject is investigated by personalization of website features with consumers' cognitive style. Website features are described with regards to the general "look and feel" of the website and the consumer's cognitive style on how to review information. For example, the customer prefers web pages with graphics features such as charts and images over text. Such web pages may be associated with more saleswhen a consumer with analytical cognitive style reads them; while most text-based web pages may be more effective when a consumer with holistic cognitive style reads them(Braun et al, 2009). Online stores which consider the cognition-based antecedents help in building trust in consumers towards the fact that the seller carefully observes the quality of products and maintains the information of purchasers as well as provide more opportunities to trust the seller (Montazeri et al., 2014).

Trustmeans mutual faith towards good intentions and behavior of others. Trust requires a cognitive leap beyond expectations for which reason and experience alone are no guarantee (Rezaeian, 2012). When people trust each other in a deal, means that they keep promises made during their business relationship (Montazeri et al., 2014). With the increase in online sales of goods and services, and the expansion of e-commerce, it is very important to build trust and distrust is one of the reasons for the low number of Internet shopping. The results show that Web 2.0 applications attract people to interact as well as produce content on the Internet. In this regard, consumers have used social e-commerce for these activities, which in turn leads to increased levels of trust and intention to purchase (Fathian and Hosseini, 2014). The more the level of consumer trust is, Their intention to purchase is higher and it will be easier for companies to maintain them. Behavior is under the influence of the behavioral intentions and tendencies (Abzari et al., 2011).

With regards to culture, it can be said that although the e-commerce and internet networks have made it possible for the users to disseminate information in electronic form worldwide, in the meantime there is a cultural challenge because consumers' behavior is under the influence of culture (Hofstede , 2001). Cultural dimensions of Hofstede (2001) include collectivism / individualism, masculinity / femininity, uncertainty avoidance, power distance and long-term / short-term tendencies, by which the customer's cultural orientations are identified (Hofstede, 2001). In this study, dimensions of collectivism / individualism and uncertainty avoidance were evaluated. According to the previous researches "it was shown that one of the factors that affect customer's trust, and as a result, affect the amount of online shopping is cultural differences. Also, customers' perceptions of the Internet company can affect the amount of online shopping ( Nejadshokoohi and Doaei, 2014). Moreover, in general the culture is an effective factor on the level of trust and intention to purchase (Celeste, 2012).

\section{Hypotheses and conceptual model development}

The purpose of this research is to measure and evaluate the correlation among these variables affecting e-commerce purchasers' behavior in social networks by taking into account the moderating influence of culture on it (Iranian online purchasers). The basic model was presented by Celeste See-Pui $\mathrm{Ng}$ in 2013 in a study titled "Intention to purchase in social commerce websites with a view on the moderating effect of culture". In this research, by taking into account the Trust Transfer Theory, the social interaction and cultural dimensions of Hofstede, it is proven that culture has a moderating effect on the intention to purchase in the social e-commerce. Also, trust plays a mediating role in the purchase intention in connection with the social interaction and the trust transfer (Celeste,2013). As new social commerce is still is still new in 
thee-commerce, attempt was made to develop the above model by studying other models and a more comprehensive model is proposed by taking into account the most effective factors on purchase intention in social networks. Based on the results of the study titled "A study on the effect of virtual communities in strengthening customer's purchasing behavior" (Fathi Hussein, 2014), the higher and deeper is the level of social identity in a virtual community, the more the sense of belonging of the members to that the community will be. Moreover, the more the sense of belonging of members to a virtual community, the more the acceptance of virtual social influence in their decisions will be. The more the trust level is among the members of a virtual community, the more sense of belonging to that community will be. Finally, it must be said that there is a positive and direct relationship between the acceptance of influence in a virtual community and the purchasing behavior of the members. Therefore, the social identity of the purchaser was added to the previous research model "purchase intention in social commerce websites with a view on the moderating effect of culture" (Celeste, 2013) and was investigated as a component affecting the trust and purchase intention. Furthermore ,according to the study titled "Evaluating determinants of the intention to purchase in e-commerce" (Montazeri et al, 2014), virtual companies can with increased attention to the cognitive, experiential, personality antecedents, and the emotional state to increase trust and reduce the perceived risk of online customers and ultimately strengthen their purchase intention. On the other hand, according to the study titled "Do website features matched with the cognitive style of consumers increase the amount of online sales?" (Braun et al, 2009), personalizing websites features based on the cognitive style of consumers will lead to increased purchasing rate. Therefore, the purchaser's cognitive style, as an important component of human interaction and information systems in the purchaser's decision-making style was added to the previous research model "Intention to purchase in social commerce websites with a view on the moderating effect of culture" (Celeste, 2013). Moreover, the cognitive style was evaluated as a component affecting the trust and purchase intention. At the end, the research model was finalized as seen in Figure 1.

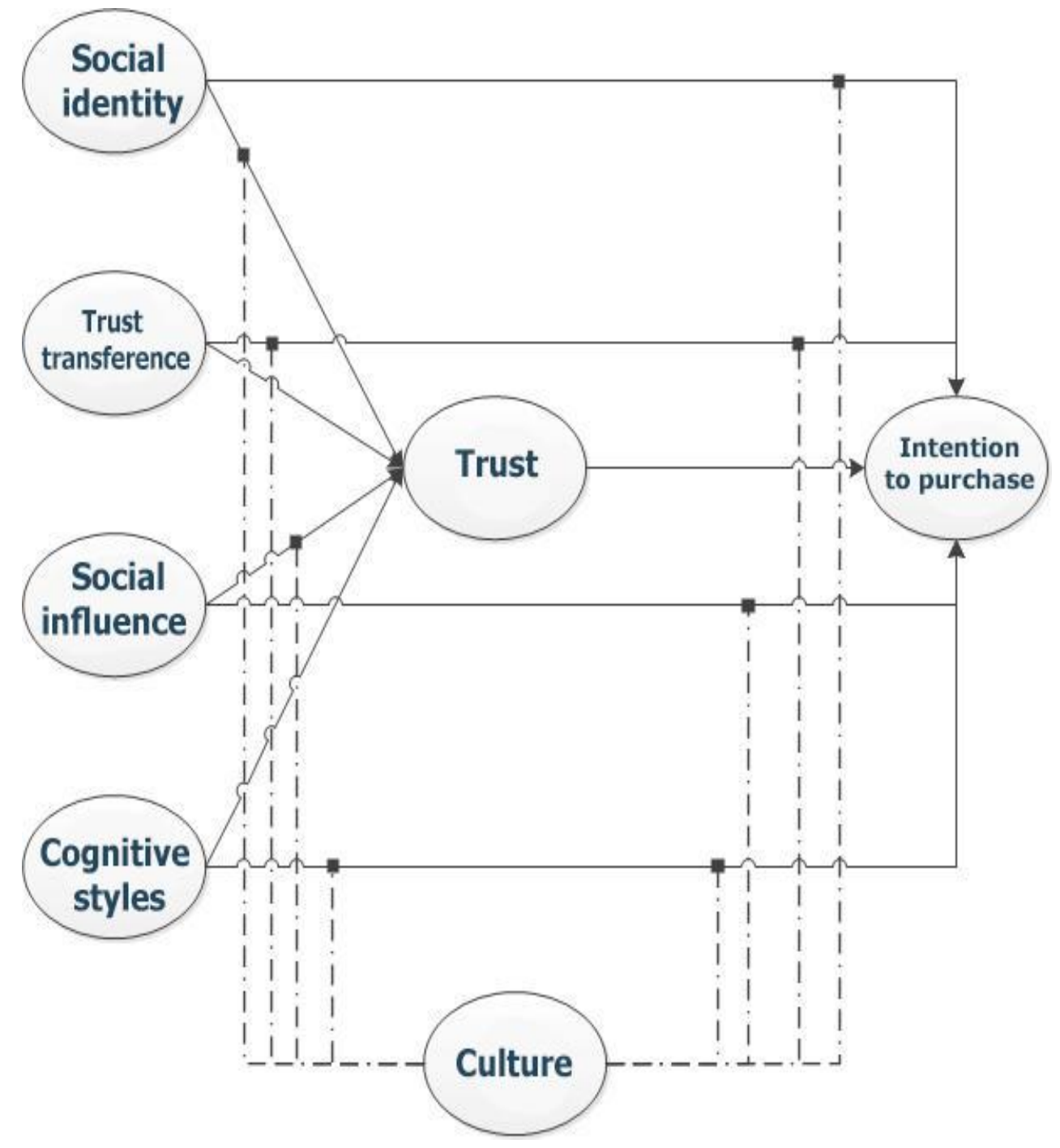

\section{Research hypotheses}

In this study, factors affecting the intention to purchase in the social networks have been studied. It is assumed that Iranian culture has a moderating effect on the intention to purchase in the social e-commerce. Also, trust plays a mediating 
role in relation to the social influence, purchase intention, trust transference, cognitive style and social identity. Therefore, the hypotheses have been introduced as follows:

\begin{tabular}{|c|c|}
\hline 1 & Social influence (feel close to) affects the intention to purchase in a social network community. \\
\hline 2 & $\begin{array}{l}\text { Trust transference affects the intention to purchase in a social network community in a social network } \\
\text { community (Familiarity). }\end{array}$ \\
\hline 3 & Social identity of a social network community affects the purchase intention. \\
\hline 4 & Cognitive styles of members in a social network community affect the purchase intention. \\
\hline 5 & Trust in a social network community affects the purchase intention. \\
\hline 6 & Social influences (feel close to) affect the trust level in a social network community. \\
\hline 7 & Trust transference (familiarity) affects the trust level in a social network community. \\
\hline 8 & Social identity of a social network community affects the trust level in that community. \\
\hline 9 & Cognitive styles of members in a social network community affect the level of trust in the community. \\
\hline 10 & $\begin{array}{l}\text { Trust in a social network community plays a mediating role in the relationship between the social influence and } \\
\text { intention to purchase from a social commerce website. }\end{array}$ \\
\hline 11 & $\begin{array}{l}\text { Trust in a social network community plays a mediating role in the relationship between the trust transference } \\
\text { and intention to purchase from a social commerce website. }\end{array}$ \\
\hline 12 & $\begin{array}{l}\text { Trust in a social network community plays a mediating role in the relationship between the social identity and the } \\
\text { intention to purchase from a social commerce website. }\end{array}$ \\
\hline 13 & $\begin{array}{l}\text { Trust in a social network community plays a mediating role in the relationship between the cognitive style and } \\
\text { the intention to purchase from a social commerce website. }\end{array}$ \\
\hline 14 & $\begin{array}{l}\text { Culture, as a different dimension of collectivism vs. individualism, plays a mediating role in the relationship } \\
\text { between the social influence, trust transference confidence, social identity and cognitive style and the intention } \\
\text { to purchase from a social e-commerce website. }\end{array}$ \\
\hline 15 & $\begin{array}{l}\text { Culture, as a different dimension of uncertainty avoidance, plays a mediating role between social influence, trust } \\
\text { transference, social identity and cognitive style and the intention to purchase from a social e-commerce website. }\end{array}$ \\
\hline
\end{tabular}

\section{Methodology}

Since this study tries to define and measure the dimensions of e-commerce purchasing behavior and its effects on the consumer's behavior in a social network and the moderating effect of culture on these dimensions; therefore, this is a survey research. Methodologically, this is a descriptive and correlational study. The population of this research is people who use social networks. Individuals have 2 properties in this study. 1. They are Iranian and use social networks in Iran. 2. since these people, to some extent have to be experts in the field of online social networks, attempt were made to choose subjects who have at least be educated in information technology or computer engineering fields. Also, library studies were used to collect secondary data in such way that the required information was collected through valid books, magazines and papers, theses. Furthermore, the cyberspace was used to review to the latest articles. Statistical data needed to test the hypotheses were obtained from distributed questionnaires analysis and secondary data was used to extract the conceptual model. In order to increase the credibility of the research, efforts have been made to distribute the questionnaire among those users who have higher qualifications and are experts in the field. For this reason, the questionnaire was distributed among employees in subsidiaries of Fanava Group. According to statistics announced by the Human Capital Management of Fanava Group, the number of employees is 818 people and 367 experts are active in the ICT field; therefore, the total population is equal to 367 people. For this study, 184-subject sample and the sample size were determined using simple random sampling method and Morgan Formula, respectively. 184 questionnaires were returned from the selected sample. The validity of the questionnaire was evaluated based on the experts' views. Moreover, to measure the reliability, Cronbach's alpha was calculated (83\%), (75\%), (80\%), $(80 \%),(81 \%)(77 \%)$ and $(71 \%)$ respectively for, trust, trust transference, cognitive style, social culture, purchase intention, the amount of social influence and social identity. These numbers indicate that the questionnaire has the reliability, or in other words, it has an adequate reliability. In this study, statistical software of Smart PLS is used for data analysis, in which issues of validity and reliability of structures and causal relationship among structures and their explanatory power are investigated, respectively in two stages of the measurement pattern and the structural pattern. Causal modeling model or structural equation model is one of the main methods for analyzing complex data structures. The subject domain of the present research is classified in the field of information technology management and in a more specialized form in the field of social networks. This research was conducted during summer and fall of 2015 by Fanava Group and its subsidiaries.

Cronbach's alpha coefficient is used for measuring the one-dimensionality of attitudes. Convergent and discriminant validity were used to assess the construct validity. To assess the convergent validity, the reliability of any of the items and 
the average extracted variance (AVE) are measured. In connection with the reliability of items, factor loading of 0.7 and above for each item represents well-defined structure. And also the factor loadings should be significant at least at the level of 0.05 (Garsen, Straub, 2005). of reliability and validity indices are shown in Table 1.

\section{Table 1. Validity and reliability indices}

\begin{tabular}{|l|l|l|l|l|}
\hline Hidden variables & AVE & Composite reliability & $\begin{array}{l}\text { Coefficient } \\
\text { determination }\end{array}$ & Oronbach's alpha \\
\hline Trust & 0.69 & 0.864 & 0.677 & 0 \\
\hline Trust transference & 0.662 & 0.855 & 0 & 0.751 \\
\hline Cognitive style & 0.831 & 0.851 & 0 & 0.808 \\
\hline Social culture & 0.521 & 0.852 & 0.331 & 0.802 \\
\hline Purchase intention & 0.526 & 0.866 & 0 & 0.81 \\
\hline Social influence & 0.622 & 0.827 & 0 & 0.778 \\
\hline Social identity & 0.664 & 0.811 & & 0.713 \\
\hline
\end{tabular}

Table 2. Pearson correlation coefficients and discriminant validity index.

\begin{tabular}{|l|l|l|l|l|l|l|l|}
\hline Hidden variables & $(1)$ & $(2)$ & $(3)$ & $(4)$ & $(5)$ & $(6)$ & $(7)$ \\
\hline (1) Trust & 1 & & & & & & \\
\hline (2) Trust transference & 0.516 & 1 & & & & & \\
\hline (3) Cognitive style & 0.689 & 0.499 & 1 & & & & \\
\hline (4) Social culture & 0.582 & 0.235 & 0.485 & 1 & & & \\
\hline (5) Purchase intention & 0.556 & 0.44 & 0.349 & 0.342 & 1 & & \\
\hline (6) Social influence & 0.552 & 0.527 & 0.438 & 0.294 & 0.384 & 1 & \\
\hline (7) Social identity & 0.688 & 0.431 & 0.646 & 0.542 & 0.32 & 0.403 & 1 \\
\hline
\end{tabular}

Table 2 shows Pearson correlation coefficients in a binary form for the relationship between hidden variables. Number 1 is assigned on the main diameter of the matrix to show that each variable is totally correlated with itself. All coefficients are significant at the confidence level of $99 \%$ (The significance level is less than $1 \%$ ). The more the value of the correlation coefficient is, the greater and stronger the intensity of the relationship between two variables will be.

Besides correlation coefficients, the divergent validity is also evaluated in Table 5.

\section{Data analysis and research findings}

In the following parts of the paper, dependent and in dependent components were be determined and analyzed according the proposed model using Smart PLS software. The numbers on the communication lines between the items and variables and the numbers on the lines of communication between the primary and secondary variables represent factor loadings and path coefficients, respectively.

\section{Diagram 1. Model with no moderator variables in a state of standard coefficients estimation}

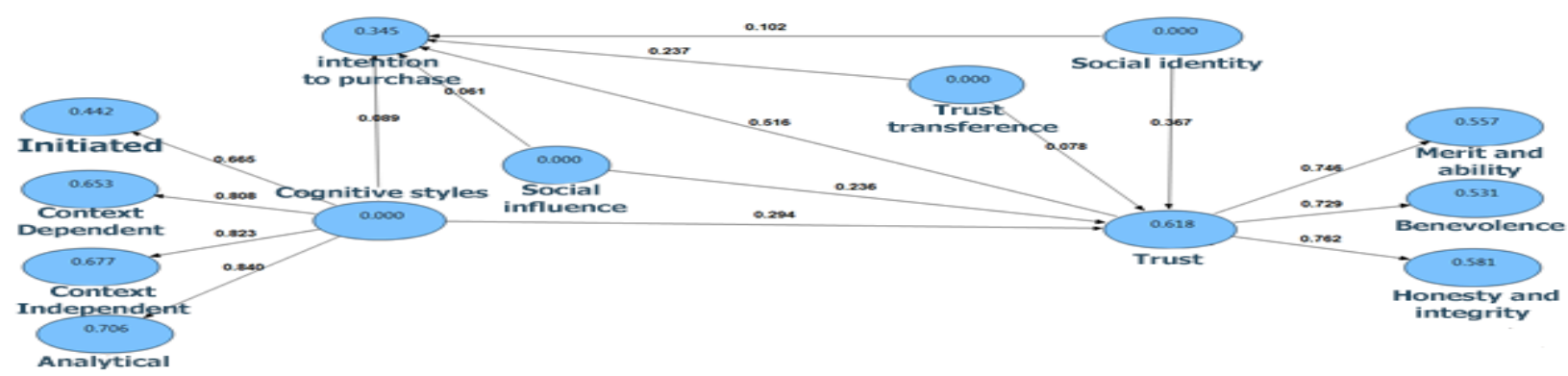


Diagram 1 shows the confirmatory factor analysis model and structural equations without moderator variable in a state of standard coefficients estimation. Variables of social identity, cognitive style, trust transference and social influence are independent or exogenous and variables of trust and purchase intention are mediator and dependent or endogenous.

\section{Diagram 2. Model with no moderator variable in a state of a significant absolute value (| T-Value |)}

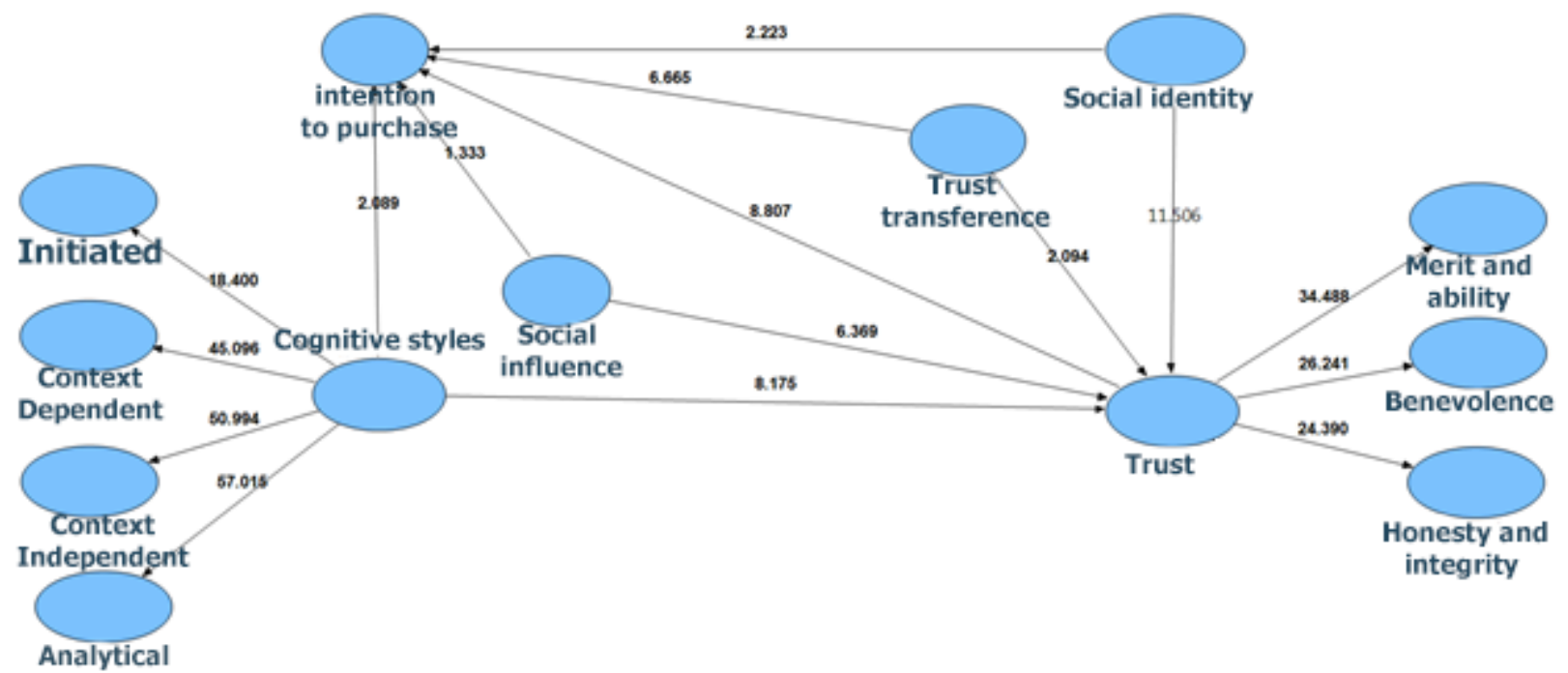

Diagram 1 shows the confirmatory factor analysis model and structural equations in a state of significant absolute value of coefficients (t-value). In fact, this model tests all the measurement equations and structural equations using the statistic $t$. According to this model, if the value of the statistic $t$ is higher than 96.1, the coefficient is significant at significance level of $95 \%$.

\section{Diagram 3. Model with moderator variable in a state of standard coefficients estimation}

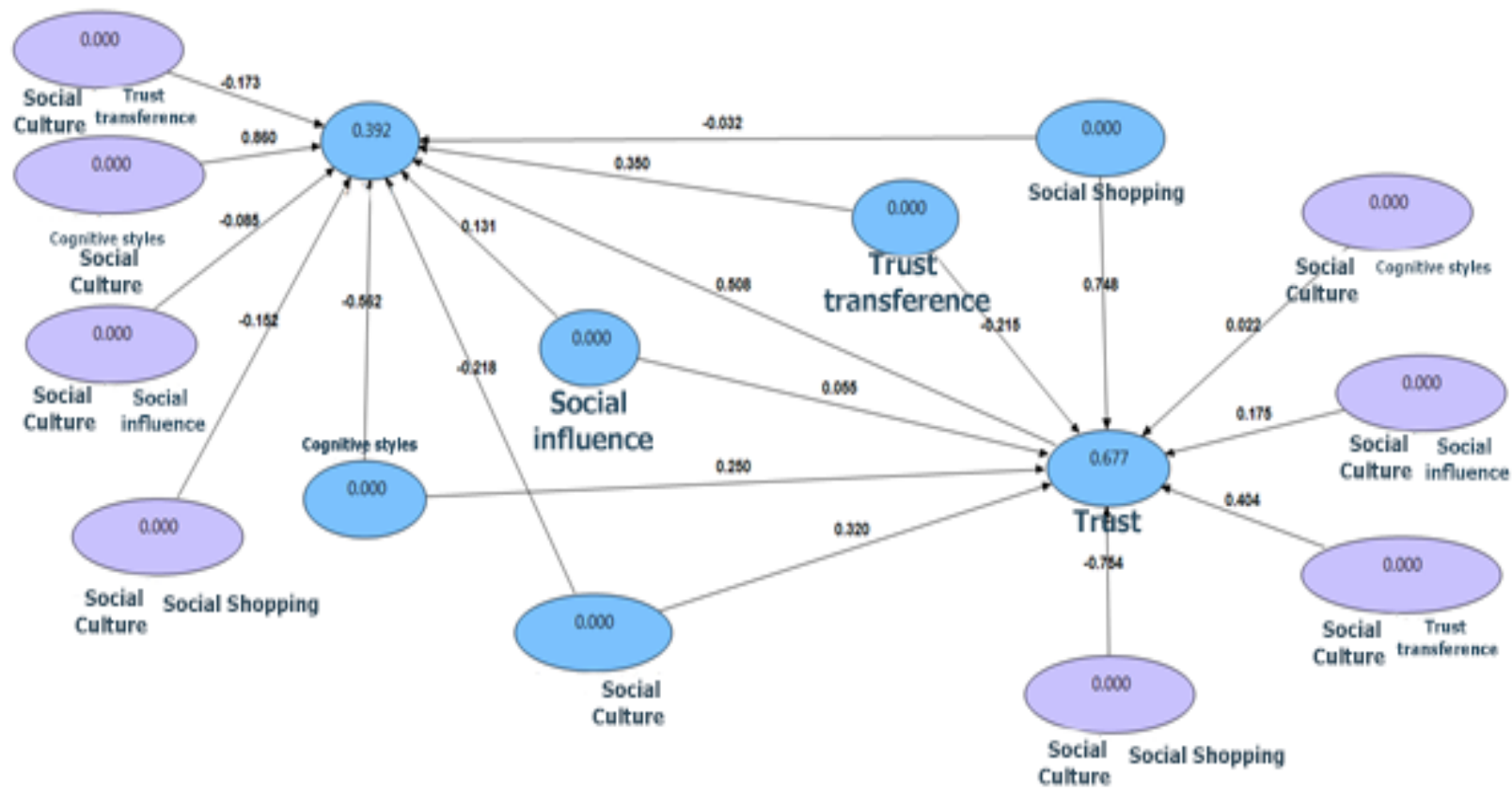

Diagram 3 shows the structural equations model in a state of standard coefficients estimation. In this model, social-cultural variable is added to the model as moderator variable to affect the relationship between social identity, cognitive style, social influence, trust and trust with the purchase intention. So in this model, social identity, cognitive style, trust transference and social influence play the role of the independent variables. Moreover, social culture, trust and purchase intention are considered as moderator, mediator and dependent variables, respectively. 


\section{Research hypotheses (direct effects)}

\section{Table 3, path coefficients, T-statistic and the result of direct effects}

\begin{tabular}{|c|c|c|c|c|c|c|}
\hline Independent & Dependent & Beta & $\begin{array}{l}\mathrm{t}- \\
\text { statistics }\end{array}$ & $\mathrm{R} 2$ & Direction of relationship & Result \\
\hline Trust & \multirow{5}{*}{ Purchase intention } & 0.517 & 8.807 & \multirow{5}{*}{0.345} & + & Confirmed \\
\hline Trust Transference & & 0.238 & 6.665 & & + & Confirmed \\
\hline Cognitive style & & 0.089 & 2.089 & & + & Confirmed \\
\hline Social influence & & 0.061 & 1.333 & & NS & Rejected \\
\hline social Identity & & 0.102 & 2.223 & & + & Confirmed \\
\hline Trust Transference & \multirow{5}{*}{ Trust } & 0.078 & 2.094 & \multirow{5}{*}{0.618} & + & Confirmed \\
\hline Cognitive style & & 0.294 & 8.175 & & + & Confirmed \\
\hline Social influence & & 0.236 & 6.369 & & & \\
\hline \multirow[t]{2}{*}{ social Identity } & & \multirow{2}{*}{0.367} & \multirow{2}{*}{11.506} & & & \\
\hline & & & & & + & Confirmed \\
\hline
\end{tabular}

$|t|>1.96$ Significant at $P<0.05,|t|>2.58$ Significant at $P<0.01$,

Hypothesis 1: Social influence (feel close to) has a significant effect on the purchase intention in a social network community. Considering the fact that $t$ value is within the confidence intervals (between -1.96 to +1.96 ), the researcher's claim is rejected at $\mathrm{P}<0.95$.

H2: Trust transference has a significant effect on the purchase intention in a social network community. Considering the fact that $t$ value is out of the confidence interval (more than 1.96) $(P<0.05)$, the researcher's claim is confirmed at $P<0.95$. With regard to the positive beta coefficients, it can be said that the trust transference has a direct and positive effect on the purchase intention in a social network community.

H3: Social identity of a social network has a significant effect on the purchase intention. Considering the fact that $t$ value is out of the confidence interval (more than 1.96) $(\mathrm{P}<0.05)$, the researcher's claim is confirmed at $\mathrm{P}<0.95$. With regard to the positive beta coefficients, it can be said that the social identity of a social network has a direct and positive effect on the purchase intention in a social network community.

H4: The cognitive style of members in a social network community has a significant effect on the purchase intention. Considering the fact that $t$ value is out of the confidence interval (more than 1.96) $(P<0.05)$, the researcher's claim is confirmed at $\mathrm{P}<0.95$. With regard to the positive beta coefficients, it can be said that the cognitive style of members in a social network community has a direct and positive effect on the purchase intention in a social network community.

H5: Trust in a social network community has a significant effect on the purchase intention. Considering the fact that $t$ value is out of the confidence interval (more than 1.96) $(P<0.05)$, the researcher's claim is confirmed at $P<0.95$. With regard to the positive beta coefficients, it can be said that the trust in a social network community has a direct and positive effect on the purchase intention.

The coefficient of determination for the purchase intention is 0.345 . So, the social influence variable (feelings of intimacy) in a social network community, trust transference in a social network community, the social identity of a social network, the cognitive style of members in a social network community and Trust in a social network community, together, could have explained 34.5 percent of changes in the purchase intention.

Considering the amount of beta coefficients, it can be said that trust has the highest contribution in a social network community (highest beta coefficients) compared with other variables and the social influence has the lowest continuation in social networks than other variables (Lowest beta coefficients). 
H6: The social influence (feel close to) has a significant effect on the level of trust in the social network community. Considering the fact that $t$ value is out of the confidence interval (more than 1.96) $(P<0.05)$, the researcher's claim is confirmed at $\mathrm{P}<0.95$. With regard to the positive beta coefficients, it can be said that the social influence in a social network community has a direct and positive effect on the level of trust.

H7: Trust transference in a social network community has a significant effect on the level of trust in that community. Considering the fact that $t$ value is out of the confidence interval (more than 1.96) $(P<0.05)$, the researcher's claim is confirmed at $\mathrm{P}<0.95$. With regard to the positive beta coefficients, it can be said that the trust transference in a social network community has a direct and positive effect on the level of trust.

H8: The social identity of a social network has a significant effect on the level of trust in the community. Considering the fact that $t$ value is out of the confidence interval (more than 1.96) $(P<0.05)$, the researcher's claim is confirmed at $P<0.95$. With regard to the positive beta coefficients, it can be said that the social identity of a social network has a direct and positive effect on the level of trust.

H9:The cognitive style of members in a social network community has a significant effect on the level of trust in the community. Considering the fact that $t$ value is out of the confidence interval (more than 1.96) $(P<0.05)$, the researcher's claim is confirmed at $\mathrm{P}<0.95$. With regard to the positive beta coefficients, it can be said that the cognitive style of members in a social network community has a direct and positive effect on the level of trust.

The coefficient of determination for the level of trust in society is equal to 0.618 . So, the social influence variable (feelings of intimacy) in a social network community, trust transference in a social network community, the social identity of a social network and the cognitive style of members in a social network community could explain 61.8 percent of changes in the level of trust in social network community. Considering the amount of beta coefficients, it can be said that the social identity has the highest contribution in a social network community (highest beta coefficients) compared with other variables and the trust transference has the lowest continuation in social networks than other variables (Lowest beta coefficients).

\section{Research hypotheses (indirect effects)}

\section{Table 4. Path coefficients, $t$-statistic and the result of indirect effects}

$|t|>1.96$ Significant at $P<0.05,|t|>2.58$ Significant at $P<0.01$,

\begin{tabular}{|c|c|c|c|c|c|c|}
\hline Independent & Moderator & Dependent & Beta & $\begin{array}{l}\text { T- } \\
\text { statistic }\end{array}$ & $\begin{array}{l}\text { Direction of } \\
\text { relationship }\end{array}$ & Result \\
\hline $\begin{array}{l}\text { Trust } \\
\text { Transference }\end{array}$ & \multirow{6}{*}{ Trust } & \multirow{6}{*}{$\begin{array}{l}\text { Purchase } \\
\text { intention }\end{array}$} & 0.123 & 4.021 & + & Confirmed \\
\hline Cognitive style & & & 0.046 & 2.114 & + & \multirow{2}{*}{ Confirmed } \\
\hline \multirow{2}{*}{ Social influence } & & & 0.032 & 1.021 & NS & \\
\hline & & & 0.053 & 2.283 & + & \\
\hline \multirow{2}{*}{ social Identity } & & & 0.123 & 4.021 & + & Rejecled \\
\hline & & & 0.046 & 2.114 & + & Confirmed \\
\hline
\end{tabular}

H10: Trust in a social network community, plays a mediating role in the relationship between the social influence and the intention to purchase from a social commerce website. Considering the fact that $t$ value is within the confidence intervals (between -1.96 to +1.96 ), the researcher's claim is rejected at $\mathrm{P}<0.95$.

H11: Trust in a social network community plays a mediating role in the relationship between the trust transference and the intention to purchase from a social commerce website. Considering the fact that $t$ value is out of the confidence interval (more than 1.96) $(P<0.05)$, the researcher's claim is confirmed at $P<0.95$. With regard to the positive beta coefficients, it can be said that this role is positive and in the same direction.

H12: Trust in a social network community plays a mediating role in the relationship between the social identity and the intention to purchase from a social commerce website. Considering the fact that $t$ value is out of the confidence interval (more than 1.96) $(\mathrm{P}<0.05)$, the researcher's claim is confirmed at $\mathrm{P}<0.95$. With regard to the positive beta coefficients, it can be said that this role is positive and in the same direction. 
H13: Trust in a social network community plays a mediating role in the relationship between the cognitive style and the intention to purchase from a social commerce website. Considering the fact that $t$ value is out of the confidence interval (more than 1.96) $(\mathrm{P}<0.05)$, the researcher's claim is confirmed at $\mathrm{P}<0.95$. With regard to the positive beta coefficients, it can be said that this role is positive and in the same direction.

\section{Research hypotheses (effects of moderator variables)}

\section{Table 5. Path coefficients, t-statistic and the result of moderator variable effect}

\begin{tabular}{|c|c|c|c|c|c|c|c|}
\hline Independent & Moderator & Dependent & Beta & $\mathrm{t}$ & $\Delta R^{2}$ & $\begin{array}{ll}\text { Direction } & \text { of } \\
\text { relationship } & \end{array}$ & Result \\
\hline Trust Transference & \multirow{8}{*}{ Social culture } & \multirow{4}{*}{ Purchase intention } & -0.173 & -0.987 & \multirow{4}{*}{0.047} & NS & Rejected \\
\hline Cognitive style & & & 0.86 & 3.57 & & + & Confirmed \\
\hline Social influence & & & -0.085 & -0.217 & & NS & Rejected \\
\hline social Identity & & & -0.152 & -0.375 & & NS & Rejected \\
\hline Trust Transference & & \multirow{4}{*}{ Trust level } & 0.404 & 2.446 & \multirow{4}{*}{0.059} & + & Confirmed \\
\hline Cognitive style & & & -0.173 & -0.987 & & NS & Rejected \\
\hline Social influence & & & 0.86 & 3.57 & & NS & Rejected \\
\hline social Identity & & & -0.085 & -0.217 & & - & Confirmed \\
\hline
\end{tabular}

$|t|>1.96$ Significant at $P<0.05,|t|>2.58$ Significant at $P<0.01$,

H14: Social pluralism culture plays a mediating role between the social influence, trust transference, social identity and cognitive style and the intention to purchase from a social e-commerce website. The results show that the moderating effect of the social pluralism culture on the relationship between the cognitive style and the purchase intention has been confirmed (the t-value is out of the confidence interval). The positive beta coefficients indicate the positive and direct nature of this effect. However, the effect of moderator variable of social pluralism culture on the relationship between the trust transference, social influence and the social identity and the purchase intention has been rejected (the $t$ value is within the confidence interval). The amount of the coefficient of determination for the purchase intention variable was 0.392 before the addition of moderator variable. The same amount reached to 0.345 with the arrival of moderator variable. So, the moderator variable of social culture has increased this amount by 4.7 percent. It must be noted that most of the changes related to the relationship between two variables of the cognitive style and the purchase intention. Considering the fact that the moderator variable was at least effective on one of the relationships of social influence, the trust transference, social identity, cognitive style and the intention to purchase from an e-commerce website, the researcher's hypothesis can be accepted at the confidence level of $95 \%$.

H15: The social culture of risk-taking plays a mediating role between social influence, trust transference, social identity and cognitive style with trust in a social network community. The results showed the effect of the social culture of risktaking as a moderator variable on the relationship between the social identity and the trust transference and trust in a social network community has been approved ( $T$ value is out of the confidence interval). The beta coefficient was positive regarding the effect of the social culture on the relationship between two variables of trust transference and trust level in the community. Moreover, the social culture negatively affected the relationship between the social identity and the level of trust in the society. The effect of the social culture of risk-taking as a moderator variable on the relationship between social influence and the cognitive style with trust in a social network community was rejected ( $T$ value is within the confidence interval). The amount of the coefficient of determination for the trust variable in a social network community was 0.618 before the addition of moderator variable. The same amount reached to 0.677 with the arrival of moderator variable. So, the moderator variable of social culture has increased this amount by 5.9 percent. It must be noted that most of the changes related to the relationship between two variables of the trust transference and the social identity with trust in a social network community. Considering the fact that the moderator variable was at least effective on one of the relationships of social influence, the trust transference, social identity, cognitive style and the trust in a social network community, the researcher's hypothesis can be accepted at the confidence level of $95 \%$.

\section{Conclusion}

The results of hypothesis with direct effects of variables on the intention to purchase in the social networks showed that there is a positive and significant relationship between trust, trust transference, cognitive style, social influence and social identity (correlation coefficient effect of 0.345 ), and the intention to purchase in the social networks. The coefficient of determination for the direct effects of variables is equal to 0.345 . So, variables of trust, trust transference, cognitive style, social influence and social identity, altogether have managed to explain 34.5 percent of the intention to purchase in the social networks. Considering the amount of beta coefficients, it can be said that the cognitive style has the highest 
contribution in a social network community (highest beta coefficients) compared with other variables and the social influence has the lowest continuation in social networks than other variables (lowest beta coefficients).

Furthermore, the results of the hypothesis with direct effects of variables on trust in social networks showed that there is a positive and significant relationship between trust transference, cognitive style, social influence and social identity (correlation coefficient effect of 0.618 ), and the trust in a social network. The coefficient of determination for the direct effects of variables is equal to 0.618 . So, variables of trust transference, cognitive style, social influence and social identity, altogether have managed to explain 61.8 percent of the trust in the social networks. Considering the amount of beta coefficients, it can be said that the social identity has the highest contribution in a social network community (highest beta coefficients) compared with other variables and the trust transference has the lowest continuation in social networks than other variables (lowest beta coefficients).

On the other hand, the results of the hypothesis with indirect effects of variables with the mediating role of trust on the purchase intention in social networks showed that there is a positive and significant relationship between trust transference, cognitive style, social influence and social identity with the mediating role of trust on the purchase intention in social networks. Considering the amount of beta coefficients, it can be said that the trust transference has the highest contribution in a social network community (highest beta coefficients) compared with other variables and the social influence has the lowest continuation in social networks than other variables (lowest beta coefficients). Moreover, considering the fact that $t$ value is out of the confidence interval (more than 1.96), the researcher's claim is confirmed is at $\mathrm{P}<0.95$.i.e "trust in a social network community plays a mediating role in the relationship between the social influence and the intention to purchase in a social commerce website.

Finally, the results of hypotheses with the effects of moderator variable of culture and variables of trust transference, cognitive style, social influence and social identity on the purchase intention and trust in social networks indicated that there is a positive and significant relationship between trust transference, cognitive style, social influence and social identity(correlation coefficient effect of 0.059 ) with trust in social networks (correlation coefficient effect of 0.047)and the intention to purchase in the social networks. So, variables of trust transference, cognitive style, social influence and social identity, altogether have managed to explain 4.7 percent of the purchase in the social networks. Considering the amount of beta coefficients, it can be said that the cognitive style has the highest contribution in a social network community (highest beta coefficients) compared with other variables and the trust transference has the lowest continuation in social networks than other variables (lowest beta coefficients). And considering the fact that variables of trust transference, cognitive style, social influence and social identity ,altogether have managed to explain 5.9 percent of trust in social networks, thus with regard to the beta coefficient value, it can be said that the trust transference has the highest contribution in a social network community (highest beta coefficients) compared with other variables and the social identity has the lowest continuation in social networks than other variables (lowest beta coefficients). Considering the features provided by the social network to their users, the possibility of interaction is established among them. So, there is the likelihood of agreeing or disagreeing with the views and behavior of others publicly and privately. It was anticipated that the social influence could create an inner state for others in this context so that they intend to purchase in the social commerce platform to their inner state with the recommendations of their influential friends. In the research titled, "intention to purchase from social e-commerce websites and moderating effect of culture" (Celeste, 2012), the assumption was effective in East Asia and was ineffective in Latin America, such as Iran. Therefore, the culture factor could play an important role by directly affecting the social and purchase intention in the context of social commerce. Considering the features provided by the social network to their users, the possibility of joining the group is established among them. Therefore, the social identity is that part of one's perception from himself/herself that originates from his consciousness of membership in a social group as well as the importance of values and its accompanying feelings. According to the results of the research, the social identity increases the level of trust and purchase intention in the social commerce. The study showed that trust may be transferred from one source to another and increase the level of trust and purchase intention in the social commerce. On the other hand, cognitive style of human and the discrepancy between the internalized perception of the environment with what has really been understood from the same environment is based on the cognitive, experiential, personality antecedents and the emotional state and increases the trust level and purchase intention .Therefore, the cognitive style increases the level of trust and purchase intention in a social commerce. It is also effective on the costumer's trust and the internet shopping. And trust as a moderator variable, plays its role among other variables affecting purchase intention. So the trust level strengthens the purchase intention in a social commerce. Finally, with regards to culture, it can be said that although the e-commerce and internet networks have made it possible for the users to disseminate information in electronic form worldwide, in the meantime there is a cultural challenge because consumers' behavior is under the influence of culture (Hofstede , 2001). In this study, dimensions of collectivism / individualism and uncertainty avoidance were evaluated. According to the results of previous researches, culture is a factor affecting customer's trust level, and the purchase intention. Culture also plays an important role as a moderator variable among other variables affecting the trust and purchase intention. In general, the social commerce and its capabilities can boost online business. On the other hand, it will be considered as an essential requirement in the online competition in the near future. Therefore, a better understanding of customer's behavior can increase online sales and boost online business. In this regard, they must completely analyze customer's behavior and the factors affecting on it. Finally, it is recommended to investigate the impact of the trust level and purchase intention in the context of social commerce in future studies. Also, considering the fact that trust plays an important role in the social commerce; therefore, it is recommended to conduct a comprehensive review on the trust in the social commerce.

Generalizing this model and studying variables affecting the purchase intention and the complex effects of behavioral stimulus of the purchase intention in emerging social e-commerce networks can help us understand the effect of social 
stimuli on the purchase intention in the social network space. Moreover, these effects should be investigated and modified in the social network fields in order to help clarify the path in this field of research.

\section{REFERENCES}

1) Abzari Mahdi, Ghorbani, Hassan, Khajehzadeh, Saman; Makinian, Elmira. (2012), "ranking factors affecting trust building in the Internet environment using Analytic Hierarchy Process Technique (AHP)", Journal of Technology Management of Management Faculty of Tehran University, No. 7, summer 2012

2) Islami, Morvarid(2012), "Study of social networks and their impact on various aspects of life", First National Congress of virtualspace and emerging social problems, Tehran, Ministry of Cooperatives, Labour and Social Welfare, No. 1, Summer 2012

3) Pirmohammadiani, روجيار, Mohammadi., Shahriar, Hosseini, Munira (2013), "The role of social commerce on behavior and purchasing decisions of customers", Special conference on aspects of social networks, Tehran, SID, Institute of Information Technology, Number 1, Summer 2013

4) Kheyri, Bahram, Jorjorzadeh, Maryam, (2013), "A Conceptual Model for theoretical study of the impact of social networks on consumer purchasing decisions", Special conference on aspects of social network, Tehran, SID, Institute of Information Technology, Number 1, Summer 2013

5) Rezaeian, Ali (2013), human interaction and information system (MIS) (Fifth Edition), SAMT Publication, Tehran

6) Rezaeian, Ali (2012), political behavior management in organizations (Advanced Organizational Behavior Management) (Seventh Edition), SAMT Publications, Tehran

7) Rezaeian, Ali (2011), Foundations and self-management approach (Advanced Organizational Behavior Management) (First Edition), SAMT Publications, Tehran

8) Rezaeian, Ali (2012), Team-building in the twenty-first century (Advanced Organizational Behavior Management) (Fifth Edition), SAMT Publications, Tehran

9) Rezaeian, Ali (2015), Management of Organizational Behavior (Ffth Edition), SAMT Publications, Tehran

10) SakhiJavareshak, Seyed Amir Hussein; Shokouhyar, Sajad; Siadati, SeyyedHossein (2015), "A model for raising the popularity level of advertising content of brands in online social media " MS Thesis on Information Technology Management in ShahidBeheshti University.

11) SabooriKhosroshahi, Habib; Azargoon, Nasrin. (2012), "The impact of virtual social networks (Facebook) on the social identity (case study: students of Islamic Azad University)", media studies, Issue 21, summer 2013

12) Sandoghdar, Afshin; Darzi, Mohammad; Ghahari, SeyedehMahdokht(2013), "long-term effects of social networks through revenue models in social network websites", Special conference on aspects of social networks, Tehran, SID, Institute of Information Technology, No. 1, summer 2013

13) Fathian, Mohammad., Hosseini, Mohammad. (2014), "Investigating the effect of virtual communities in strengthening customers purchasing behavior", Journal of Journal of Information Technology Management, Management Faculty of Tehran University, No. 3, Fall 2014

14) Mahmoudi, Alireza., Mahmoudi, Mojtaba.; Torkashvand, Parvin (2015), social networks: Aspects and concepts (Second Edition), Sacco Publications, Tehran

15) MesbahiJahromy, Ngaralsadat; AkhavanKharazian, Maryam (2014), "Investigating the effect of planned behavior factors on online shopping behavior", especially a National Marketing First Conference, April 2014

16) Masumi Larry, Seyed Ali and Husseini, Monireh (2012), "Classification of Web 2.0 business models and their relationship with the characteristics of Web 2.0," Information Technology Management, Tehran University, No. 3, fall 2014

17) Montazeri, Mohammad, Ebrahimi, Alireza. Ahmadi, Parviz, Rahnama, Ameneh (2014) "Evaluation of factors influencing purchasing intention in the e-commerce", Journal of Business Management, Faculty of Management, Tehran University, No. 2, summer 2014

18) Nejadshokouhi, Fatemeh; Doaei, Habiballah (2014), "Effects of Hofstede's Cultural Dimensions on customer's trust in online shopping by mediating the customer's perception of the company", Journal of Organizational Culture Management, Issue 1, Spring 2014

19) NiknejadKhasmakhi, Maryam (2012), Social commerce, Ameh Publications, Tehran

20) Niknejad, Maryam; Jalali, Ali Akbar; Dastgheybifard, Gholamhossein; Akbarian, Reza. (2011), "Designing an acceptable model for social business development in Iran", the Conference on Information Technology and Economic Jihad, Kazeroon, Kazeroon Higher Education Complex, Number 1, summer 2011 